\title{
Is Dandelion Rubber More Natural? Naturalness, Biotechnology and the Transition Towards a Bio-Based Society
}

\author{
Hub Zwart • Lotte Krabbenborg • Jochem Zwier
}

Accepted: 22 February 2015/Published online: 5 March 2015

(C) The Author(s) 2015. This article is published with open access at Springerlink.com

\begin{abstract}
In the unfolding debate on the prospects, challenges and viability of the imminent transition towards a 'Bio-Based Society' (BBS) or 'Bio-based Economy'-i.e. the replacement of fossil fuels by biomass as a basic resource for the production of energy, materials and food, 'big' concepts tend to play an important role, such as, for instance, 'sustainability', 'global justice' and (last but not least) 'naturalness'. The latter concept is, perhaps, the most challenging and intriguing one. In public debates concerning biotechnological interactions with the natural environment, the use of terms such as 'nature' and 'naturalness' is both inevitable and hazardous (given the fact that they are so notoriously difficult to define). Indeed, various conflicting interpretations of naturalness play a role on both sides (pro- and con) of the current debate. This paper aims to analyse and critically assess the role of 'nature-speak' in the BBS transition. We will begin with a concise overview of the vicissitudes of the nature-concept so far, focussing on how modern science and technology have challenged and affected our understanding of what nature is. Subsequently, we describe how 'naturalness' functions in the unfolding BBS debate. Finally, we will focus on a particular case study, namely the production of rubber with the help of natural latex coming from dandelion plants rather than from (tropical) rubber trees. On the one hand, this is presented as a more natural and naturefriendly way of producing rubber. On the other hand, it is a sophisticated process, involving high technology and primarily focussed on competitiveness on the global market. To what extent or in what sense can dandelion latex be regarded as more
\end{abstract}

H. Zwart $(\bowtie) \cdot$ L. Krabbenborg · J. Zwier

Department of Philosophy and Science Studies, Faculty of Science, Institute for Science, Innovation and Society (ISIS), Radboud University Nijmegen, Nijmegen, The Netherlands e-mail: h.zwart@science.ru.nl

L. Krabbenborg

e-mail: 1.krabbenborg@science.ru.nl

J. Zwier

e-mail: j.zwier@science.ru.nl 
natural? And what can we learn from this case study when it comes to addressing naturalness in the broader conceptual and bio-political arena?

Keywords Naturalness $\cdot$ Bio-based society $\cdot$ Biotechnology

\section{Introduction}

In the unfolding debate on the prospects, challenges and viability of the imminent transition towards a 'Bio-Based Society' (BBS) or 'Bio-based Economy' (BBE) i.e. the replacement of fossil fuels by biomass as a basic resource for the production of energy, materials and food, 'big' concepts tend to play an important role, such as, for instance, 'sustainability', 'global justice' and (last but not least) 'naturalness' (Asveld et al. 2011, p. 12, 77-78). The latter concept is, perhaps, the most challenging and intriguing one. In debates concerning biotechnological interactions with the natural environment, the use of terms such as 'nature' and 'naturalness' is both inevitable and hazardous (given the fact that they are so notoriously difficult to define). Various conflicting interpretations of naturalness play a role in the current debate. ${ }^{1}$ With its emphasis on circularity and renewability ('zero waste'), the biobased turn appears to move in the direction of a more 'natural', or at least more nature-friendly mode of producing energy, materials and food, more attuned to natural processes (both on the macro- and on the micro-scale) and therefore less disruptive. It is perceived as the end of what Spengler (1918/1923) and others have termed the 'Faustian' era (an epoch of frantic exhaustion of resources, massive pollution and exponential growth). And yet, highly advanced ('post'-GM) biotechnologies, bent on controlling nature through the modification and commodification of living organisms, notably at the molecular level, are bound to play an important role in the envisioned bio-based transition. In other words, a bio-based production system would be 'more natural' (in the sense of: interacting with natural processes in more sensitive, less disruptive ways) but at the same time 'un-natural' (being dependent on highly advanced biotechnologies that are currently emerging). Against this backdrop, the concept of nature/naturalness may prove a conceptual hurdle (a bone of contention), but also a 'conceptual tool' that may allow us to strengthen and think through the potentials, prospects and challenges of bio-based production (van Haperen et al. 2012).

This paper aims to analyse and critically assess the actual and possible roles of 'nature-speak' in the current BBS debate. We will begin with a concise overview of the vicissitudes of the nature-concept so far, focussing on how modern science and technology have challenged and affected our understanding of what nature is. A similar dynamics can be discerned in how the term 'biotechnology' has evolved,

\footnotetext{
1 "Notions about naturalness play a key role in the debate about the bio-economy because they are related to various opposing positions taken up in the debate... Notions of naturalness clearly inform the views of those taking part in the debate, although such notions generally smoulder beneath the surface" (Asveld et al. 2011, p. 77-78. The authors briefly discuss three conflicting positions, which they term the romantic, the utilitarian and the controlling view of nature.
} 
notably in recent years. For indeed, in contemporary scientific discourse, the idea has emerged that nature and biotechnology (the 'natural' and the 'biotechnological') should no longer be seen as antagonistic, but rather as merging in the sense that human biotechnology increasingly aims to mimic nature (Benyus 1997; van der Hout 2014, p. 199-122), that is: to imitate, as minutely as possible, the 'biotechnologies' developed by nature herself, while nature is being perceived in an outspokenly technical way, namely as an outdoors biotechnological 'laboratory' of enormous complexity and immense proportions.

Subsequently, we will describe in outline how 'naturalness' functions in the evolving BBS debate. Important notions such as circularity, zero waste and biomimesis suggest that the basic objective of the bio-based turn is to development smart(er) technologies, allegedly more attuned to the processes and dynamics of nature than their (more disruptive, more Faustian) predecessors.

Finally, the empirical part of our paper will focus on a particular case study, namely the production of rubber (as a key economic resource) with the help of natural latex derived from Dandelion plants rather than from (tropical) rubber trees, a process which is currently under development. Notably we will focus on one particular example, the dandelion project of an international biotech company named KeyGene, based in the Netherlands, although we will refer to similar, contemporaneous projects as well, such as the collaboration between Fraunhofer Institute in Aachen (Germany) and tire company Continental AG, and between chemical company DuPont and tire company Goodyear. We will analyse how the 'naturalness' and 'greenness' of dandelion rubber projects (which actually involves fairly sophisticated lab work) is presented to stakeholders and consumers, notably on websites. We focus on websites because (with their careful wordings, epigrammatic statements and telling illustrations) we regard them as strategic podiums where the current debate on naturalness is staged and enacted before a global audience. The broader conceptual debate outlined above may learn from such close examinations of how the nature-concept functions in concrete contexts. For indeed, when it comes to discussing naturalness issues, various routes can be taken. One possibility would be to opt for a top-down approach, starting from the concept of nature in philosophical discourse, analysing and defining it, and then 'applying' it to the bio-based discourse as such. In this article, however, although we will start with a conceptual assessment, we will eventually combine it with a 'bottom-up' case study approach.

Protagonists explicitly present the dandelion case as a major contribution to the transition towards a BBS. Therefore, it exemplifies a debate of much broader import, namely the quest for an upgraded (critically reconsidered) concept of nature, in combination with a critical reflection on the (often fairly strategic) uses of 'naturalness' as an argument in the current BBS/BBE debate. In other words, although the production of 'natural' rubber from dandelions (as a substitute for unsustainable tropical rubber) is interesting in its own right, we will explicitly place it in the broader context of current efforts to use ('hypermodern') technoscience to make the bio-based transition more sustainable and 'natural', namely via a 'greening' of agricultural and industrial production systems. 
Thus, in the following sections we will move stepwise from the conceptual level (discussing the concepts of 'nature' and 'biotechnology' as such), via the biopolitical level (discussing the use of these concepts in the context of the bio-based turn) down to the biotechnological level (the role of 'nature' and 'naturalness' in the dandelion case, in which highly sophisticated biotechnological tools are deployed to produce 'greener', more 'natural' rubber).

\section{Conceptual Level: The Obliteration of Nature by 'Hypermodern' Technoscience}

The term 'nature' has become something of a conceptual embarrassment. In every-day language, it is used easily and frequently, and in a broad variety of contexts, carrying various (often fluid) connotations. The same applies to its various derivatives, such as 'natural', 'naturalness', 'naturally', etc. Indeed, one could say that 'nature-speak' (Zwart 1994) is still a fairly ubiquitous component of contemporary discourse, notably in the public sphere.

And yet, we no longer seem to know what nature is. The term 'nature' seems impossible to define, as G. W. F. Hegel already noticed in his Philosophy of Nature, where he argues that nature has become a conceptual "enigma", both intimidating and alluring. And although we perhaps hope that the natural sciences (so astonishingly successful in exploring and understanding the processes of nature) will help us to address the question what nature is, their input remains unsatisfactory, so that the issue keeps recurring. ${ }^{2}$

On the one hand, nature is often taken to refer to the non-human, i.e. that which thrives and exists without our doing, that which adheres to its own 'laws', that which is not produced by human technology or culture (Aristotle 1980). This Aristotelean concept was reframed by Lee (2003) as Nature ${ }_{\mathrm{fa}}$ : i.e. nature as a "foil", a contrasting backdrop to everything artificial, nature as that which occurs without the involvement of human agency (p. 16). On the other hand, human beings, as biological organisms, are evidently part of nature as well. Like other entities, moreover, we may be said to 'have' a nature, in the philosophical sense of the term: human 'nature' as the essence of what we are. Somehow, after centuries of use (and abuse), the term 'nature' seems to have become worn out and emptied, more or less, to such an extent that several contemporary philosophers, ethicists and social scientists have argued to eradicate it altogether, at least from scholarly vocabularies (Vogel 1996). ${ }^{3}$ We seem to have lost the articulacy needed to effectively and convincingly address the question what nature is, we seem to have lost our conceptual proximity to and affinity with nature altogether, so that the term defies

\footnotetext{
2 "Was ist die Natur? Die Frage wollen wir uns durch die Naturkenntnis beantworten. Wir finden die Natur als ein Rätsel und Problem vor uns, das wir ebenso aufzulösen uns getrieben fühlen, als wir davon abgestoßen werden ... Wir sammeln Kenntnisse über die mannigfaltigen Gestaltungen und Gesetze der Natur; dies geht in ein unendliches Detail hinaus; und eben weil kein Ende darin abzusehen ist, so befriedigt uns dieses Verfahren nicht. Und in allem diesem Reichtum der Erkenntnis kommt uns die Frage von neuem: Was ist die Natur? Sie bleibt ein Problem." (1830/1970, p. 12).

${ }^{3}$ For an overview of this debate, see Zwart (1994).
} 
current efforts towards conceptual upgrading. And yet, we continue to use it, both inside and outside academia. Indeed, the concept of nature is recalcitrant and continues to force itself upon us. We are unable or unwilling to leave it behind, notwithstanding the daunting conceptual difficulties involved. An exercise in retrieval seems therefore preferable to an attitude of avoidance. Perhaps it will still be possible to come up with a critically assessed and conceptually 'cleansed' version of the term, suitable for both scholarly and public use, via a process of conceptual 'catharsis'. This is the route to which this paper aims to contribute.

When it comes to understanding the vicissitudes of the concept of 'nature', resulting in its current (deplorable) condition, the role of modern science and technology must be duly underscored. In the nineteenth century, during the 'Faustian era', powerful machines allowed humans to exploit natural resources on a massive scale, while steamers and trains opened up realms of nature which previously seemed inaccessible. In laboratories and factories, the sway of human intelligence and dexterity over nature seemed unlimited. It was (not coincidentally) during this period that the 'philosophy of nature' (metaphysics) deteriorated into a discipline in statu moriendi.

This process was further amplified in the twentieth century when quantum physics discovered the elementary particles of energy and matter, while molecular genetics discovered the elementary particles of life (such as nucleotides, amino acids and genes). One of the landmarks of this development was the year 1953 no doubt, when Edmund Hillary and Tenzing Norgay (for the first time in history) reached the summit of the Mount Everest, while James Watson and Francis Crick discovered the molecular structure of DNA. Nature seemed subdued, from the highest mountain peak down to the most elementary units of life. Not coincidentally, I guess, it was in this same year that Heidegger concluded that more than ever before, science determines how nature presents itself to us. ${ }^{4}$

Notably, the molecular plasticity of nature has significantly increased, due to 'biotechnology', i.e. the translation of molecular biological insights into applications in medicine, agriculture and industry. Interestingly, in ancient Greek, the term 'elements' ( $\sigma \tau \mathrm{o} \chi \chi \varepsilon i \alpha)$ not only refers to the basic constituents of nature, but also to the letters of the alphabet. And indeed, during the twentieth century came to be described with the help of specialised alphabets, such as the letters referring to genes (Aa, Bb, Cc, etc.), or the 4-letter alphabet of nucleotides (A, C, G and T), or the alphabet of elementary particles physics $\left(\mathrm{e}^{-}, \mathrm{P}^{+}, \mathrm{H}^{+}, \mathrm{H}^{\mathrm{o}}, \mu\right.$, etc. $)$, or the alphabet of amino acids (Ala, Arg, Asn, Asp, etc.). This not only made it possible to break down the phenotypical complexities of (living) nature into data sets that can be assembled, stored, quantified, analysed and manipulated with the help of computers ('in silico', Thacker 2005), but it also gave rise to the emergence of a new and outspokenly 'technical' way of viewing nature: namely nature as a molecular (biotechnological) laboratory of gigantic proportions. And the human bioengineer, who has entered this laboratory, merely seems to use the tools provided by nature

\footnotetext{
4 "Die Wissenschaft ist eine entscheidende Weise, in der sich uns alles, was ist, darstellt. Die Wirklichkeit wird nach ihren Grundzügen in zunehmenden Maße durch das mitbestimmt, was man die abendländisch-europäische Wissenschaft nennt” (Heidegger 1953/1954, p. 45).
} 
herself, such as restriction enzymes, the molecular 'precision scissors' with the help of which genetic engineers refurbish life by adding or subtracting particular genetic features: by 'splicing in' or 'knocking out' targeted genes.

As a consequence of this, 'natural' nature, i.e. nature as that which is fundamentally different from technology and functions and evolves in natural environments outside laboratories (and their artificially produced forms of 'objectivity') seemed to evaporate. Or rather: by understanding (living) nature in terms of elementary particles (represented by codes and 'letters'), life and nature (as we once knew it) became literally obliterated. Indeed, it can hardly be a coincidence that the decline of nature as a concept (as outlined above) closely coincided with the scientific unravelling of nature's molecular 'essence' in the laboratories of modern science. One might even argue that the abundant use (in moral deliberations and public debate over food, energy and the environment) of terms such as 'nature' and 'naturalness' amount to 'compensation': a public response to the conceptual eclipse of nature brought about by the dominance of this techno-scientific unfolding of nature, the modern technological way of revealing what nature is, of bringing nature to the fore (to frame it in Heideggerian terms (Heidegger 1953/1954). As Lee (2003) has argued, molecular biology (or 'deep' biology, as she calls it) gave rise to an ontological transformation of living organisms from natural beings into "biotic artefacts". Nature has become humanised to such an extent that natural evolution is now superseded by human manipulation of biotic nature. ${ }^{5}$ And still, Heidegger assures us that, when all is said and done, nature will remain the 'unsurmountable' ("das Unumgängliche", 1953/1954, p. 62). Indeed, in the final instance, nature is the Real, i.e. that which can never be wholly captured in terms of scientific objectivity.

This implies that, when it comes to critically assessing, redefining or even revivifying the concept of nature, the present scientific understanding of nature (which actually represents one particular, albeit highly influential way of viewing nature) cannot be taken for granted. Rather, we must become sensitive to the complexities of the conceptual landscape in which the term 'nature' functions nowadays. Nature-speak in the public arena may either be pervasively contaminated by the scientific, objectifying view, or it may amount to a (desperate?) effort to move away from (now dominant) techno-scientific definitions of what nature is (such as the idea that nature can be regarded as an immense and awesomely sophisticated laboratory-that can be mimicked and copied in highly advanced human laboratories around the globe). At the same time, because the nature-concept has lost much of its former conceptual clarity and depth, it may easily fall prey to strategic use and rhetorical exploitation.

These developments concerning 'nature' are mirrored by similar debates concerning the meaning of what (until recently) was usually regarded as nature's antagonistic counter-concept, namely 'biotechnology'.

\footnotetext{
5 And this 'humanisation of nature' concurs with a 'naturalisation of human', a redefinition of human nature in terms of molecular biology (Lee 2003).
} 


\section{Is biotechnology 'Natural' or 'Artificial'/Human?}

The debate on 'nature' and its conceptual discontents is mirrored by a congruent uneasiness concerning the term 'biotechnology'. Until recently, 'nature' and 'biotechnology' tended to be seen as conceptual opposites, in the sense that biotechnology was regarded as something outspokenly human (that is: 'unnatural', Cf. Zwart 2009). But this has evidently changed. As a result of the molecular turn in the life sciences (outlined above), nature as such is now increasingly seen as a profoundly biotechnological phenomenon in its own right. It is now claimed, for instance, that the basic tools and techniques of contemporary biotechnology (which are put to work in life sciences laboratories) were developed by nature herself billions of years ago.

Is biotechnology $3,500,000,000$ or rather 35 years old? Notwithstanding the vast time difference between these two answers, both of them can be regarded as essentially correct, depending on the way in which 'nature' and 'biotechnology' are defined. For those who opt for the first answer, microbes (such as cyanobacteria) are the real bioengineers, while human bio-engineers merely 'plagiarise' and adopt the inventions of these microbial pioneers (Ohno1987; Church and Regis 2012). If we follow this line of thinking, then all the basic biotechnological processes and techniques currently in use in science were already developed billions of years ago and tested and refined in the course of evolution. Indeed, human biotechnology is basically 'mimicry' and 'plagiarism'. To continue to see ourselves as the inventors of biotechnology would be an instance of self-centredness and short-sightedness.

For those who opt for the second answer, however, technology in general, and biotechnology in particular, remain typically human phenomena, conducted in highly artificial environments known as laboratories. Whereas the work of microbes is blind, pre-programmed and repetitive, genuine (human) biotechnology is conducted in a purposeful way, guided by negotiations, deliberations, commercial interests and bio-molecular knowledge. As a consequence, biotechnology is unnatural (Reiss and Straughan 1996; Rifkin 1998/1999). This 'anthropocentric' answer still adheres to the ancient idea, formulated by Aristotle (1980) almost twenty-five centuries ago, that nature (i.e. that which emerges and moves on its own account, without our doing) must be distinguished from technology and culture (i.e. that what human beings do). In other words, the second answer adheres to the basic ontological distinction between the natural and the artificial, between biology and technology, between 'in vivo' and 'in vitro'.

Besides these two 'extreme' responses, other, more 'intermediary' responses can be given, such as the response that biotechnology is about 10,000 years old: as old, in fact, as the domestication of plants and animals and the use of microbes such as yeast for fermentation purposes (biotechnology in the low-tech, craft-based, artisanal sense of the term). In other words, the answer to the question concerning the birth of biotechnology can be framed in terms of (a) billions of years (microbes as bio-engineers), (b) millennia (farmers as artisanal bio-engineers) and (c) decades (molecular bio-tech experts as bio-engineers). The latter two answers uphold a distinction between non-human and human versions of bio-technology. 
Those who opt for the first answer, namely that biotechnology is about $3,500,000,000$ years old (and in our experience the large majority of contemporary life scientists belongs to this category), will find this latter distinction between human and non-human biotechnology difficult to uphold. In their understanding, nature emerges as a vast, highly advanced and complex outdoors laboratory. This is the new image of nature that has come to dominate contemporary scientific discourse. A quite outspoken and radical example of it can be found in the book Regenesis: How synthetic biology will reinvent nature and ourselves, written by science celebrity George Church, in collaboration with science journalist Ed Regis (2012):

Cohen and Boyer were not the world's first (nor even the most successful) genetic engineers. That distinction belongs to viruses, particularly bacteriophages - essentially a sting of DNA or RNA wrapped in a protein (p. 45).

Seen from this perspective, biotechnology is as old as life itself. It has always been there, although until recently it has remained beyond our scope. It was present in nature in a latent, diffuse way, as the molecular 'depth' of natural processes, but now it is finally brought to the fore, is made manifest and discrete, and appropriated by (human) biotechnology. That which used to be a mere foil or backdrop of

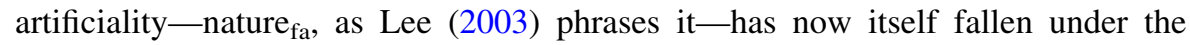
sway of human intervention, but for authors such as Church and Regis this does not make human biotech 'unnatural', quite the contrary. Mutual interference, thoroughgoing reciprocity of life-forms, pervades nature as such. Living entities are constantly re-sculpting one another: that is part of the dynamics of nature (Lee 2003, p. 17), and human pervasiveness may be seen as an example of this.

In other words, the question whether biotechnology is 'natural' or 'unnatural' may give rise to various incompatible answers. This is clearly visible in the public arena as well, where 'naturalness' plays an important role in debates concerning biotech, food and the environment. As Sagoff (2003) points out, for instance, companies often emphasise the 'naturalness' of their (biotechnologically produced) products, knowing that this is something consumers tend to find important. Advertisements and labels assure them that the food products they buy are (almost) nature-identical, although actually, they are often highly processed products, whose large-scale availability depends on fairly advanced technology (p. 12). Still, producers frame their products as natural because they use "nature's own methods" (p. 15). From their perspective, genetic engineering is natural, at least as natural as conventional biotechnologies that enabled humanity to engage in agriculture $\sim 10,000$ years ago. In short, conflicting views of what nature is and what biotechnology is are at work here. Whereas a more or less 'nostalgic' vision wants products to be as untainted by technology as possible, a science-oriented view believes that naturalness can in fact be achieved by mimicking nature through biotechnological means. ${ }^{6}$

\footnotetext{
6 Sagoff even quotes a passage from Shakespeare's The Winter's Tale, where Polixenes (in a dialogue with Perdita, a young shepherdess who praises naturalness) explicitly questions the difference between 'art' (artificiality) and 'nature': "[That art] which you say adds to Nature, is an art/That nature makes... The art itself is nature".
} 
Thompson (2003) suggests to solve these misunderstanding with the help of what he refers to as the "artisanal" conception of the natural (p. 29). According to this conception, food products are natural as long as they are produced by artisanal farmers whose 'green fingers' are sensitive enough to collaborate with nature without "going against the grain" of nature. This amounts to the view that whereas traditional (artisanal) biotechnology is natural, recent (molecular and genetic) biotechnology is not. But, as we will see in our case study, some high-tech voices claim that a revival of artisanal sensitivity to nature (albeit under hypermodern conditions) is precisely what highly advanced technologies currently purport to achieve. And yet, they seem very far removed from a truly artisanal, more or less intuitive rapport with nature.

In short, the question whether biotechnology is 'natural' or 'unnatural' does not seem the type of question that can be settled with the help of a few conceptual clarifications. Rather, we are confronted with a metaphysical collision, a 'gigantomachia' even, as Plato framed it: a fundamental struggle between incommensurable understandings of what 'nature' is. We may see the naturalness-debate as an exemplification of what Lyotard (1983) referred to as a 'differend', a clash between different language games, grounded in incommensurable understandings of nature. In short, the various answers to the question presented above are backed up by incommensurable ontologies. This conceptual struggle over basic concepts such as 'biotechnology' and 'nature' entails more than merely 'food for philosophers', however. It has gained new impetus in recent years, notably in the context of the debate over the imminent bio-based 'turn', the advent of the BBS, enthusiastically applauded by some, but criticised and problematized by others.

\section{The Bio-Political Level: Is 'Bio-Based' More 'Natural'?}

According to advocates of the bio-based transition (a broad coalition of scientists, policy-makers and experts from industry), what is envisioned under headings such as BBS or BBE is a more natural and sustainable way of producing food and energy: more attuned to natural processes, and therefore less disruptive for the environment (European Commission 2012). Others (sceptics and critics) rather see it as a further intensification of our biotechnological sway over nature, symptomatic for today's humanity's refusal to critically reflect on its blatant consumerism and exploitationism (Lemmens 2014). Birch et al. (2012) argue that BBE protagonists frame the issue of sustainability in terms of a technocratic 'master narrative', bent on solving problems via technological fixes. In a similar vein, in the final report of the European CREPE project (2011) it is argued that BBE production systems are basically envisioned as biomass mass-factories. Moreover, it is pointed out that conflicting accounts of nature are at stake. Whereas BBE promotors tend to reduce society-nature relations to competitive advantages in global markets, especially through agro-industrial monocultures, market-oriented economics and high-tech corporate knowledge, opponents rather see natural resources as a commons to be 
protected (p. 10). ${ }^{7}$ Framed in this manner, the bio-based turn rather emerges as a new chapter in our Faustian quest for control, so that the ideal of 'naturalness', when used in favour of this development, is employed in a rather ideological fashion.

It is not yet possible to ascertain with certainty in which direction the bio-based transition is evolving. This is, as yet, an open-ended bio-political question. But what is already clear is that the success or failure of the bio-based transition will not only depend on the development of effective technologies. Sensitivity to the complex subtleties of the conceptual landscape in which the bio-based debate is taking shape will prove important as well. This will be underlined by our analysis of the dandelion rubber case study. It is important to notice, first of all, that concepts such as 'nature' and 'naturalness' play a role at both sides of the BBS debate: they are used by pro- as well as by con-voices. In other words, the debate on the bio-based turn cannot be framed as a struggle between protagonists and antagonists of naturalness. Rather, it is a debate in which various perspectives on naturalness (various understandings of 'nature') are involved, and this may easily give rise to a Babylonian 'confusion of tongues'. Whereas scientists, for instance, often argue that there is no detectable difference between the 'natural' and the 'non-natural' on the molecular level (since the chemical formula for ingredients such as colorants for instance will be basically the same regardless of whether they are produced by the plants themselves or added by clever chemistry), for many consumers 'naturalness' has nothing to do not with chemical formula or molecular components. Rather, they are more likely to view terms like 'nature' and 'naturalness' as an expression of a certain basic attitude towards nature as a common heritage, which may be perceived as present in 'slow' agriculture, but as lacking in the high-tech mass food industry (in other words: the 'artisanal' view on nature referred to above).

The implication is that, in order for the shift towards a BBS to work (to really initiate a reform of agriculture and industry in a more 'natural' direction), sensitivity to 'language' will prove of key importance. In the 'multi-lingual' public sphere, where 'heteroglossia' (i.e. a plurality of-often fragmented-moral vocabularies) reigns, signifiers such as 'naturalness' and 'nature' may refer to completely different concepts, involving quite different associations. ${ }^{8}$ This can be further elucidated with the help of a few examples.

One important concept in BBS discourse, which seems closely related to naturalness, is 'circularity'. According to 'believers', the BBS is ideally a zerowaste society. Much attention is given to the conversion of waste into (renewable) products. In a recent report it is claimed that "the sun is the main source of energy, and clever logistical planning prevents even a cell of biomass from being lost" (Asveld et al. 2011, p. 24, our italics). As circularity is often seen as a characteristic of natural systems, the envisioned circularity of a future BBS may be regarded as an indication that the idea of naturalness (the striving for a more 'natural' production system) functions as an important component of the bio-based ideal (Zwier et al. 2015).

\footnotetext{
7 For an overview of critical positions see McCormick and Kautto (2013, pp. 2596-2599).

${ }^{8}$ The term (signifier, S) 'nature' may look quite 'big' and solid, but the concept signified by it (s) may actually prove quite fluid and flexible (S/s). This explains the actual 'instability' of the concept.
} 
The circularity of a future BBS contrasts, moreover, with the non-circularity of the unsustainable ('Faustian') fossil fuel epoch: a period of rapid growth, pervasive industrialisation and massive destruction of natural habitats (whose onset coincided with the start of industrial revolution during the final decades of the Eighteenth Century). The disruptive dynamics of the Faustian era are exemplified by a wellknown mathematical figure, namely the exponential curve. What at first sight may 'simply' seem a basic geometrical tool has in recent decades become a most unsettling symbol, a foreboding of doom and destruction, of a man-made cataclysm, function as a key feature of influential reports such as The Limits to Growth (Meadows et al. 1972), published under the auspices of the Club of Rome. ${ }^{9}$ The new circularity must put an end to excessive pollution, relentless exploitation and devastating deforestation of the past, indicated by the unsettling image of the exponential curve, which symbolises exponential (Faustian) expansion.

Thus, the concept of circularity exemplifies the post-disruptive dynamics of the BBS on the macro-level. But it is flanked by a similar idea of nature-friendliness on the micro-level (the molecular level). Indeed, a similar shift towards naturalness can be discerned in the form of the transition towards a 'greening' of biotechnology; towards a 'chemistry for life'. On this level, bio-mimesis or bio-mimicry (Benyus 1997) has become an important concept: the ability to learn from nature, mimicking the processes and materials nature herself has produced and adopted in the course of evolution, integrating the techno-sphere with the biosphere in more intimate and sensitive ways (Ball 2001; Bensaude-Vincent et al. 2002; McDonough and Braungart 2002; Sloterdijk 2001; van der Hout 2014). In the Faustian era, technology basically functioned as an intrusion, with polluting and disruptive sideeffect. But the future of bio-technology, it is argued, belongs to bio-mimesis. A new chemistry of life will allegedly contribute to restoring more sustainable, more 'natural' patterns.

But again, a more sceptical stance can be taken as well. The BBS debate may well be 'infected' by the remarkable optimism that permeates emerging technoscience research fields such as synthetic biology. As Bensaude-Vincent and BenoitBrowaeys (2011, p. 7 ff.) have argued: whereas doom-speak has become a ubiquitous ingredient of the current Zeitgeist, notably in the West, in synbio discourse blatant optimism is still the rule. This is clearly discernible in publications such as Church and Regis (2012) already mentioned. According to these authors, refurbished and reprogrammed microbial life forms are expected to solve most if not all of our problems, within a decade or so, via the greening (the 'biologisation') of industry. In the near future, they argue, industrial strains of proprietary microbes will produce clean energy, create bio-plastics, clean up polluted areas and detect and eradicate malignant cancer cells on the spot. Something seems to be lost in this type of promise-dense discourse: the complexity and obstinacy of living nature. Yet, rather than opting for a general ('academic') critique, we prefer to study this debate on the level of a case study.

\footnotetext{
9 This is how it functions, for instance, in the novel Inferno by Dan Brown: "Our current path is a pretty simple formula for destruction: an exponential progression occurring within a system of finite space and limited resources. The end will arrive very abruptly" (215).
} 
Thus, in order to elaborate our argument, we will now focus on a particular 'file' or case: the production of rubber out of dandelions, allegedly a more natural and sustainable way of producing an important resource, used in around 30,000 consumer products world-wide. On the one hand, dandelion rubber seems more natural and less ecologically disruptive, making use of natural latex in a more efficient and nature-friendly way, while reducing pressures on tropical rain forests. On the other hand, the employment of highly advanced biotech tools may rather strengthen the artificiality and un-naturalness of this process in the eyes of broader audiences and potential consumers. This gives rise to the question: in what way is dandelion rubber more 'natural'? How are 'nature' and 'naturalness' framed and envisioned in this context? And what can we learn from this case study concerning the bio-based debate on a more comprehensive conceptual and bio-political level?

To make these questions more concrete, we will focus on a number of dandelion rubber projects that are claimed to promote sustainability. One example concerns a German private-public venture (a collaboration of Fraunhofer Institute with Continental AG). The collaboration of chemical company DuPont and tire company Goodyear using "renewable raw materials" for bio-based tire production is another example. ${ }^{10}$ But we will notably discuss a Netherlands-based bio-tech company called KeyGene, which has started a commercial venture with the US tire company Kultevat and the Dutch tire company Apollo Vredenstein. All these initiatives claim to contribute to the production of (more) natural rubber. We will explore how terms such as 'naturalness', but also closely related terms, such as 'greenness', are actually used. As these project are still on-going and in a relatively early stage, we will focus on the way these projects are announced and envisioned on websites. We opt for dandelion rubber as a case study because, although still under development, it makes the conceptual and bio-political paradoxes of naturalness quite tangible. We opt for websites as a primary source of information because, with their careful wordings, epigrammatic statements and telling illustrations, they inform us not only about the What? and the How? of these projects, but also about the Why? (the 'teleological' dimension as it were).

\section{Bio-Based Rubber: Some Examples}

Rubber is an intriguing substance for various reasons. Broadly speaking, two versions are available: natural and synthetic rubber, although options for replacing natural by synthetic rubber are limited. ${ }^{11}$ Whereas natural rubber is primarily extracted from Hevea trees (notably the Pará rubber tree, Hevea brasiliensis, grown in South East Asia and other tropical forest areas), synthetic rubber is made of petroleum. Although rubber is of global strategic importance and used as raw material in thousands of consumer products, its production is currently under threat. First of all because the worldwide demand for natural rubber is increasing, but also because of climate change and fungal disease, to which Hevea trees are highly

\footnotetext{
${ }^{10} \mathrm{http} / / / \mathrm{www}$. goodyear.com/cfmx/web/corporate/media/news/story.cfm?a_id=646.

${ }^{11} \mathrm{http} / /$ ec.europa.eu/eip/raw-materials/en/content/european-natural-rubber-substitute-guayule.
} 
vulnerable (Mooibroek and van Beilen 2010). Tires are still by far the most important rubber product. As a recent study indicates, the tire manufacturing industry accounts for almost $60 \%$ of the global rubber consumption, both natural and synthetic (Brentin and Sarnacke 2011).

From the very beginning, the production of rubber has been beset with political, social, and economic conflicts, for instance because increasing global demand for rubber often led to exploitation of workers on rubber tree plantations (cf. Tully 2011). More recently, both policymakers and rubber consumers (notably tire manufactures) are increasingly concerned about future prospects for the natural rubber supply in view of political conflicts in Asia and elsewhere (Finlay 2009; Mooibroek and van Beilen 2010). The growing demand for rubber leads to shortages and rising rubber prices (ETRMA 2011). The production of natural rubber is also under threat due to climate change (e.g. draughts, hurricanes, floodings) and fungal disease (Mooibroek and van Beilen 2010). Therefore, various initiatives have been launched, notably public-private-partnerships (PPP) between academia and industry, to study and develop bio-based alternatives. This has led to a global quest for bio-based rubber, in the expectation that the bio-based turn will result in more environmental-friendly products.

Notably, international tire companies are moving in this direction. In 2008 for example, the chemical company DuPont and the tire company Goodyear agreed on a research collaboration to produce a bio-based alternative to synthetic rubber, called Biolsoprene ${ }^{\mathrm{TM}}$. According to a corporate press release published by Goodyear, bio-based tires will prove an important advancement, allowing the company to reduce its carbon footprint: "Finding a replacement for oil-derived materials is the right thing to do from a business standpoint, but it is also the right thing to do for the environment". ${ }^{12}$ Other tire and rubber companies such as Bridgestone and Michelin are also joining the race to develop bio-based tires. In 2012, Bridgestone for example created a partnership with Ajinomoto (a Japanese company) to jointly manufacture synthetic rubber from biomass. In 2013, Michelin and the Tereos Group jointly initiated the "Bio Butterfly" program with the overall aim to investigate the use of agricultural renewable materials, such as straw and beets, in the production of tires. ${ }^{13}$ Let us now focus on some of these projects in more detail, namely two projects that involve the use of dandelion plants as a latex resource.

\section{Dandelion Rubber 1: The Fraunhofer Project}

One of the most promising options seems the use of dandelion plants as a natural resource of latex (rubber). One dandelion project is currently conducted by the Fraunhofer Institute for Molecular Biology and Applied Ecology (IME) in Aachen (Germany), in collaboration with tire manufacturer Continental AG. Fraunhofer is

\footnotetext{
12 Jean-Claude Kihn, Chief Technical Officer for The Goodyear Tire \& Rubber Company. Source: http:// www.goodyear.com/cfmx/web/corporate/media/news/story.cfm?a_id=646).

13 http://www.sugaronline.com/website_contents/view/1224722.
} 
one of the largest European application-oriented research institutes. Its slogan is "We invent the future". ${ }^{14}$ The joint project officially started in October 2013. Its basic objective is to produce natural rubber in a much more sustainable and costeffective manner, using dandelions that can grow in areas that are unsuitable for (other forms of) agriculture, such as the steppes of Kazakhstan.

On the Fraunhofer website, the dandelion is introduced with a hint of nostalgia: "Anyone who has picked dandelions as a child will be familiar with the white liquid that seeps out of the stalks as you break them off_-Viscous, sticky." The dandelion is part of the everyday human life-world: a plant that apparently invokes sympathy, triggering childhood memories of summer days long ago, although other associations are possible as well, such as the image of dandelions as an "intruding" and "horrible" weed ("People think of Dandelions as a horrible weed ... rather than as a promising source of rubber for tires"). ${ }^{15} \mathrm{Be}$ this as it may, their viscous, sticky liquid, the vegetative 'mother milk' of nature as it were, actually contains a sought-after material of considerable economic value: natural latex. The Fraunhofer website informs us that something like 30,000 everyday products are made of rubber. ${ }^{16}$ Rubber ('caoutchouc') plantations in tropical areas, however, have a devastating impact on nature, notably in terms of deforestation. To grow immense stretches of dandelion on the plains of Kazakhstan (where this species is already endemic) seems more natural, at least more nature-friendly. This natural latex will be ready at hand and easy to process. "Researchers have genetically modified the dandelion", the website tells us, but "their next step will involve cultivating the optimized plants using conventional breeding techniques". In other words, after a brief high-tech intervention (a minimal exposure to molecular technologies), natural techniques will take over: increased naturalness also on the biotechnological level as such. Moreover, the website informs us that "the dandelion rubber has not caused any allergies so far, making it ideal for use in hospitals", an indication perhaps that it may indeed be seen as quite natural (and therefore better adapted to human bodies).

And yet, this brief exposé already points out that the concept of nature plays a fairly ambiguous role in this debate. On the one hand, the idea of naturalness is used to foster sympathy for this new development. Producing rubber from dandelion juices seems a fairly natural thing to do. It is already there: on offer by nature herself. On the other hand, less-natural aspects are clearly involved. Some forms of genetic modification (as an archetypically 'unnatural' technique) will have to be employed. And what about the Kazakhstan steppes? Will it result in the loss of natural habitats and ecosystems? By stressing the naturalness of the project on the 'manifest' level, while eclipsing its 'latent' less-natural aspects, suspicion rather than sympathy may be aroused among outsiders and future consumers. We will encounter this same paradox in the KeyGene version, discussed in the next section.

\footnotetext{
14 http://www.fraunhofer.de/en/about-fraunhofer.html [consulted: August 2014].

15 http://www.reuters.com/article/2014/08/20/us-dandelion-rubber-idUSKBN0GK0LN20140820 (Consulted: December 2014].

16 Ironically, whenever the word 'rubber' is used in every-day culture, for instance in novels or movies, it usually refers to one particular product, condoms. What traditional sexual morality would reject as 'unnatural', disrupting the natural connection between sex and procreation, plays a different role in the context of the bio-based debate, where dandelion condoms may be presented as 'natural'.
} 


\section{Dandelion Rubber 2: The KeyGene Project as a Case Study}

A similar project (producing rubber from dandelion syrup) is conducted by a commercial biotech company named KeyGene. Its core activity is developing and selling novel methodologies to produce 'high quality, high yield, pest and stress resistant crops' (www.keygene.com). The company is based in the Netherlands but operates worldwide. ${ }^{17}$ Its key motto is quite telling:

The natural way to add value to your crops. ${ }^{18}$

The company's 'passion', moreover, is framed in a similar vein:

KeyGene's passion is a Green Gene Revolution approach to explore and exploit natural genetic variation in vegetable and other $6 \mathrm{~F}$ crops. ${ }^{19}$ KeyGene is keeping its footprint as small as possible by contributing naturally to the improvement of crops [our italics]. ${ }^{20}$

Elsewhere on the company's website, the objectives are quite clearly spelled out: "It's a green gene revolution: sustainable molecular genetic responses to the world's need for yield stability, quality and health of crops". ${ }^{21}$ These website presentations, we argue, merit a closer reading. They already reflect, in a rather condensed and symptomatic way, the ambivalent role which the concept of naturalness may actually play in the context of the bio-based turn.

Let us begin with the basic motto, presenting the KeyGene approach as "The natural way to add value to your crops". On the one hand, the idea that value must be added to crops already seems to convey the idea that nature is open to significant improvement (in other words: a bio-engineering approach, seeing nature as raw material to work with, but in need of bio-technological optimisation). And as the name KeyGene itself already suggests, this value-adding will be achieved by using the latest molecular genetics techniques, focussing on 'key' genes. The term 'value' also makes it clear that economic benefit is at stake. On the other hand, and this is where the paradox comes in-the motto suggests that the process of value-adding can and should be done in a 'natural' way. The word 'natural' even comes first. In other words, value must be added by using nature's own (molecular genetic) techniques, by deploying nature's own bio-technological resourcefulness. Nature is not simply a resource (to be exploited), but a resourceful bio-engineer (from whom we can learn and with whom we may interact).

Thus, a paradox unfolds, from the very start. On the one hand, nature is the model, in accordance with the old ideal of nature as the teacher of the human arts

\footnotetext{
17 "KeyGene has its headquarters in Wageningen, the Netherlands, a subsidiary in Rockville, Maryland, USA and a Joint Lab at the Shanghai Institute of Biological Sciences in Shanghai, China. With more than 140 employees KeyGene performs strategic and applied research in a dynamic work environment with state of the art facilities and equipment". http://www.keygene.com/about-us/ [Consulted: August 2014].

18 http://www.keygene.com/ [Consulted: August 2014].

19 6F means: Food, Feed, Fiber, Fuel, Flower, Fun.

${ }^{20}$ http://www.keygene.com/about-us/ [Consulted: August 2014].

21 http://www.keygene.com/ [Consulted: August 2014].
} 
and sciences ('Natura artis magistra'). The idea of seeing human technology as 'aping' nature ('Ars simia naturae') is actually quite old, historically speaking, and this idea now seems to make a come-back. Innovation should adhere to natural pathways.

On the other hand, the objective clearly is to transform and optimise nature, and to move beyond what nature herself has on offer. Something (surplus value) must be added, with the help of the latest biotechnological tools. Yet, due to the sensitivity and sophistication of these new bio-technological tools, they are bound to leave a 'minimal footprint': the biotechnological version of 'minimalism', as it were. In this manner, these apparently antagonistic basic components (naturalness on the one hand, biotechnology and economic profit on the other) can be synthesised into one project.

A similar ambiguity is entailed in the other slogan already cited:

It's a green gene revolution: sustainable molecular genetic responses to the world's need for yield stability, quality and health of crops.

Here, it is the term 'green' which draws our attention. A similar paradox comes into view. On the one hand, the term 'gene revolution' hints at highly advanced genetic biotechnology, while the term 'revolution' may even be associated with disruptive processes of the Faustian era (entailing a series of industrial revolutions, culminating in the biotechnological one). Thus, the phrase 'gene revolution' seems to be in stark contrast with the basically circular and slow (evolutionary) processes of nature. But then, the alliterating term 'green' is added to 'gene', playing a similar role as the term 'natural' in the quotes discussed above. And again, it is the term 'green' which comes first.

The term 'green' has a long and intriguing history in philosophical discourse, moreover. The prominent medieval scholar, abbess and composer Hildegard von Bingen (1098-1179) used viriditas ('greenness') as a symbol for life, fecundity, vitality, lushness, health, harmony and divine creation (Newman 1998; KingLenzmeier 2001). In current discourse, greenness often functions as a symbol and synonym for naturalness. For that reason, it has been adopted by 'green' political parties, for instance, and by global NGOs like Greenpeace. The idea, apparently, is that naturalness (or: 'greenness') and genetic biotechnology are no longer to be seen as juxtaposed to one another. Somehow, the tension can be overcome. These polarised, antithetical extremes can now be reconciled at a higher level of aggregation (in the dialectical sense of being 'sublated' or aufgehoben), so that a new chapter in the history of biotechnology can be opened up, in the form of 'green' (natural) biotech.

Indeed, it sounds like Hegelian dialectics: slow, traditional agriculture ('thesis') was disrupted by the biotech revolution (genetic modification as the 'negation', as 'anti-thesis'). But now, these former antagonists are to be reconciled in the form of a 'green' (i.e. natural) genetic revolution (as 'synthesis'), so that a greener, more natural version of bio-tech emerges (the 'negation of the negation'). An 'Aufhebung' (abolishment, sublation) of the collision (between nature and bio-technology), combining the best of both worlds, now seems within reach. The disruptive onesidedness of 'traditional' GM (exemplified by the biotech revolution of the 1990s, 
referred to by Church and Regis as the "early stone age of DNA engineering" (2012, p. 33), will be abolished in the sense of 'aufgehoben' (brought on a higher level) and replaced by an eagerness to really understand nature ${ }^{22}$ and to allegedly mimic and observe her (green and natural) molecular pathways in technologically more refined ways.

At the same time it is clear that this positioning of 'naturalness' and 'greenness' at the very heart of their mission has a strategic or even rhetorical value for KeyGene. One of KeyGene's main interests is the acquisition of patents and licenses to maintain competitive advantage. With the 'trauma' of the 'traditional' GM debates of the 1990s in mind, KeyGene anticipates that European consumers are (still) hesitant to buy GM products. In addition, using GM techniques for crop improvement is, at least in Europe, surrounded by regulatory mine-fields. According to KeyGene, this may cause severe delays in launching their products onto the global market. So, from a commercial point of view, the label GM is not attractive. It is far more appealing to search for alternatives, like 'green' molecular genetics, which fit within the broader vision of the BBS. As the CEO of KeyGene stated in an interview: "The Biobased Society is a business opportunity for us, not an end itself".

Besides other projects, such as the 'black velvet petunia' project and the 'pollen plus' project, the dandelion project figures as an important exemplification of the new bio-techno approach. According to the KeyGene website, $90 \%$ of the world's rubber production comes from South-East Asia. Here "rain forests are stripped" to make room for rubber plantations while, due to increased consumption in China and India, a dramatic increase in demand is to be foreseen. This is likely to have a highly disruptive impact on what is still left of South-Asian tropical forests. In order to overcome this deadlock, the dandelion project seems the optimal way out. The roots of the Russian dandelion contain large amounts of natural latex. With the help of traditional breeding techniques, in combination with cutting-edge bio-technologies such as sequenced-based genotyping and key-point mutation breeding, tailored variants can be produced at a high pace to increase yields.

The further we descend into the details of the project, the more outspoken the ambiguity becomes. On the one hand, growing rubber in moderate climates in order to reduce deforestation in the tropics seems a more natural, at least a more naturefriendly path to take, in the context of global biodiversity and sustainable development. Moreover, the technologies involved exemplify the desire to build on natural processes (natural techniques, natural 'biotechnology') on a molecular level as closely as possible. Highly advanced techniques such as automated sequencing are presented as support acts to speed-up, but not to significantly change, 'traditional' breeding procedures. And yet, in order to achieve this, living entities (plants) are seen and described in fairly technical terms, as agro-genetic 'resources'. They appear, in the more technical subsections of the website, in the form of rows of symbols, indicating genetic sequences (MSH4, RPA3, TFIIH, TFB2, TFB3, TFB4,

\footnotetext{
22 Or, in the language of Church and Regis, contemporary biology seems really bent on understanding the processes of life, as well as the molecular text (DNA) in which the score of life is written; and this will give rise to more empathy with nature, even at the molecular level, culminating in the question "What is it like to be a cell?" (2012, p. 39).
} 
CCL1, Kin28, etc., etc.). We are informed that researchers are currently browsing the dandelion genome for individual genes that control some 'less-than-ideal' but alterable features, to be selected for improvement, resulting in a 'precisely enhanced product' (using technologies such as 'mutation breeding', 'sequenced based genotyping' and 'digital phenotyping'). ${ }^{23}$ By defining and describing the dandelion plants in terms of genetic data and bio-molecular symbols, the living, visible plant (as a recognisable 'Gestalt', a childhood memory even) becomes obliterated. Nature is re-described in terms of the symbol-dense vocabularies of molecular biology and functional genomics. And the end result is not the natural plant, but rather a refurbished make-over, a streamlined, optimised version, ready to be manufactured on a massive scale. Keekok Lee already predicted this when she argued that, under the sway of new waves of 'deep' biotechnology, even dandelions are bound to be transformed (irreversibly) into "biotic artefacts", biotic "machines" (2003, p. 27).

There may be nothing particularly 'wrong' with that as such. Rather, it seems to reflect the current scientific way of studying an opening-up living nature. Still, it may make it difficult to see how such procedures can be presented as 'natural'. Biotechnology as such is bound to leave its fingerprints on all its products. At least in a symbolical sense, these streamlined plants are 'tainted' by cutting-edge technologies. Thus, in KeyGene's efforts to develop a 'natural' way of adding value, nature as we know it (the living, recognisable dandelion plant as a living being, a Gestalt) gradually disappears from view, to give way to an engineering, bar-code approach to life.

\section{Dandelion Fields Forever? Concluding Remarks}

This paper addressed the question whether projects such as the KeyGene dandelion project interacts in a more natural (sensible, sensitive, nature-friendly and sustainable) way with nature, using techniques that are more attuned to natural processes as such. Are KeyGene's key technologies nature-made? Or is the KeyGene dandelion project rather to be regarded as an effort (even more pervasive, perhaps, than traditional GM) to gain control over nature, down to the deepest, molecular level? A similar question pertains to the macro-level of debate. What impact will the project have in the long run on the current ecosystems and habitats of Kazakhstan? Will central Asian steppes be transformed into dandelion fields and if so, can we somehow balance the losses of such a development against the envisioned macro-ecological gains (in terms of: decreasing the pressure on tropical rain forests)? And, finally, on the conceptual level, what progress have we made in our 'interminable analysis' of the question What is nature?

On the molecular level, companies such as KeyGene employ 'next generation' biotechnologies to escape the GM-label. Basically, they argue: yes, we are a biotech firm, but we no longer use GM, we are beyond that now, GM is something of the past ('stone age biotechnology', as Church and Regis phrase it). We are using new techniques such as 'mutation breeding', 'sequenced based genotyping' and 'digital phenotyping' that are already part of the genetic and molecular toolboxes of the

\footnotetext{
$\overline{23}$ http://www.keygene.com/products-tech/keypoint/ [Consulted August 2014].
} 
plants themselves. Whereas genetic modification in the traditional sense (the transfer of genes from the genome of one particular species to another) was indeed unnatural, with the help of these new techniques, trans-species gene-transfer can be circumvented. Basically, this means that traditional breeding (hybridisation) is assisted and accelerated but not fundamentally altered by using of these novel approaches.

Sceptics may nonetheless argue that, instead of being 'more natural', these new processes may even be regarded as 'less natural'. An important difference between past and present (between the GM era of the 1990s and the current situation) is not the use of specific GM or post-GM techniques as such, but rather the fact that biotechnological procedures are now streamlined into ready-at-hand toolboxes for industry on a fairly large scale. Instead of transforming the molecular functioning of a limited numbers of species, these techniques can now be efficiently applied to a wide range of bioforms, producible in massive quantities.

A similar tension seems at work on the bio-political (or geo-political) level. In regions such as Kazakhstan, dandelions are native ('natural') species. The impact of current rubber production on rain forests is quite disruptive, while the impact on the landscape of Kazakhstan is expected to be much more balanced and cyclical: notably because dandelions constitute an easily renewable resource. Thus, the overall net result will be more nature-friendly. Still, a more comprehensive geopolitical assessment seems called for.

Finally, for critics and sceptics, the term 'nature' may not refer to basic technologies (either GM or post-GM), but rather to basic 'attitudes'. Concepts such as 'nature' and 'the natural' are often associated with 'low tech', 'local' and 'slow', in contrast to 'high-tech', 'high speed' and 'profit' (in other words: the 'artisanal' view of nature). The more the technologies involved are explained in detail, the less 'natural' (in terms of 'low-tech', 'local', 'slow') they are likely to appear.

In short, projects such as the KeyGene dandelion initiative have a Gestalt-switch profile. On the one hand, they entail an obliteration of nature, a profound and deepseated technological view of nature, seeing living entities as molecular machines, while whole landscapes (tropical forests and steppes) are subjected to geo-economic computations. Technology has really become a Heideggerian Gestell, reducing nature to a pure resource, a new final step in the utopian/dystopian dream of complete control over nature. The 'naturalness' of nature is emptied out, 'real' nature is obliterated, and the fact that 'nature' as a concept has apparently become an empty signifier is a symptom of this process. Nature is seen from an anthropocentric, exploitative stance. From this perspective, the quest for 'greenness', 'cleanness' and 'naturalness' is merely an inevitable, compensatory terminological by-product of high-tech productivity.

On the other hand, there is more to bio-mimesis than rhetoric alone, it is more than an instance of new-speak (designed in order to avoid the GM-label), more than mere power play. There is some room for some optimism as well. These new technologies do have the potential to reduce disruptiveness, as we have seen. Biotechnology has becoming an indispensable factor in our quest for sustainability and naturalness. Heideggerian Gelassenheit refers to the possibility of consciously using post-artisanal technologies without adopting the exploitative attitude they 
seem to convey. Although the high-tech terminology and imagery provokes uneasiness, the dreadful prospect of ongoing ecological disruption calls for a pragmatist stance. In other words, an on-going reflection on our basic normative stance towards nature is not made superfluous once smarter technologies are available. Rather, the conceptual and the technological should continue to evolve as parallel tracks. BBS is not a matter of technology and technoscience only, but obviously involves cultural, societal and linguistic dimensions as well, and we may re-naturalise technology as we progress. Case studies such as dandelion latex may help us to develop a new kind of fluency or articulacy in critically assessed and updated forms of 'nature-speak', allowing us to enhance the interactive dialogue between what is happening in the labs on the one hand and the concerns and hopes of future consumers on the other.

Ultimately, the concept of naturalness refers to a basic attitude towards nature, to the question: what is driving this process? Is it the quest for control over the living, the basic technological urge to strengthen our sway over nature with the help of the latest techno-tools, seeing bio-based approaches as more profitable in the end? Or does the bio-based turn rather represent a desire to 'collaborate with' and 'learn from' nature by taking a less anthropocentric and exploitative stance? This eventually seems to determine whether or not BBS in general, and applications such as dandelion rubber in particular, will prove more natural, and whether the concept of naturalness will work as a promoter rather than as an obstacle for bringing about the bio-based turn. Evidently, there is no clear 'we' in this process, as multiple forces seem at work. Still, 'conceptual diagnostics' can be one of them.

Acknowledgments This article combines results from a research project on responsible innovation and the bio-based transition (funded by the Netherlands Organisation for Scientific Research, NWO) with results from a parallel project on the philosophical dimensions of biomaterials that was part of the research program of the Centre for Society and Genomics (CSG), funded by the Netherlands Genomics Initiative (NGI).

Open Access This article is distributed under the terms of the Creative Commons Attribution License which permits any use, distribution, and reproduction in any medium, provided the original author(s) and the source are credited.

\section{References}

Aristotle (1980) Aristotle 4: Physics 1-4. The Loeb classical library. Cambridge: Harvard University Press/London: Heinemann.

Asveld, L., Est, R., \& van Stemerding, D. (2011). Getting to the core of the bio-economy: A perspective on the sustainable promise of biomass. The Hague: Rathenau Institute.

Ball, P. (2001). Life's lessons in design. Nature, 409, 413-416.

Bensaude-Vincent, B., \& Benoit-Browaeys, D. (2011). Fabriquer la vie. Où va la biologie de synthèse. Paris: Éditions du Seuil.

Bensaude-Vincent, B., Arribart, H., Bouligand, Y., \& Sanchez, C. (2002). Chemists and the school of nature. New Journal of Chemistry, 1, 1-5.

Benyus, J. M. (1997). Biomimicry: Innovation inspired by nature. New York: HarperCollins.

Birch, I., Levidow, L., \& Papainoannou, T. (2012). Sustainable capital? The neoliberalization of nature and knowledge in the European 'knowledge-based bio-economy'. Sustainability, 2, 2898-2918. 
Brentin R., Sarnacke P. (2011). Rubber compounds: A market opportunity study. http://soynewuses.org/ wp-content/uploads/Rubber-Compounds-MOS-Sept-2011.pdf. Consulted January 23, 2015.

Church, G., \& Regis, E. (2012). Regenesis: How synthetic biology will reinvent nature and ourselves. New York: Basic Books.

Commission, European. (2012). Innovating for sustainable growth: A bioeconomy for Europe. Brussels: European Commission.

Co-operative Research on Environmental Problems in Europe (CREPE). (2011). Agricultural innovation: Sustaining what agriculture? For what European bio-economy? http://crepeweb.net/wp-content/ uploads/2011/02/crepe_final_report.pdf

European Tyre \& Rubber Manufacturers' Association (ETRMA). (2011). Position paper: An effective and delivering raw materials policy: A cornerstone for industry competitiveness and the EU resource-efficiency targets. http://ec.europa.eu/environment/resource_efficiency/pdf/ETRMA.pdf. Consulted January 23, 2015.

Finlay, M. R. (2009). Growing American rubber: Strategic plants and the politics of national security. New Brunswick, NJ: Rutgers University Press.

Hegel, G. W. F. (1830/1970). Enzyklopädie der philosophischen Wissenschaften im Grundrisse. Zweiter Teil: Die Naturphilosophie mit den mündlichen Zusätzen. Werke 9. Frankfurt am Main: Suhrkamp.

Heidegger, M. (Ed.). (1953/1954). Wissenschaft und Besinnung. In Vorträge und Aufsätze (pp. 45-70). Pfullingen: Neske.

King-Lenzmeier, A. H. (2001). Hildegard of Bingen: An integrated vision. Collegeville, MN: The Liturgical Press.

Lee, K. (2003). Philosophy and revolutions in genetics. Deep science and deep technology. New York: Palgrave MacMillan.

Lemmens, P. (2014). Taking care: Open source biotech in light of the need to deproletarianize agricultural innovation. Journal of Agricultural and Environmental Ethics, 27(1), 127-152.

Lyotard, J.-F. (1983). Le Différend. Paris: Les Éditions de Minuit.

McCormick, K., \& Kautto, N. (2013). The bioeconomy in Europe: An overview. Sustainability, 5(6), 2589-2608. doi:10.3390/su5062589.

McDonough, W., \& Braungart, M. (2002). Cradle to cradle: Remaking the way we make things. New York: North Point Press.

Meadows, D. H., Meadows, G., Randers, J., \& Behrens, W. W, I. I. I. (1972). The limits to growth. New York: Universe Books.

Mooibroek, H., \& van Beilen, J. (2010). EU-based production and exploitation of alternative rubber and Latex sources; EU-PEARLS (FP7; P212827). https://www.wageningenur.nl/en/Publication-details. htm?publicationId=publication-way-333838333933

Newman, B. (1998). Voice of the living light: Hildegard of Bingen and her world. Berkeley: University of California Press.

Ohno, S. (1987). repetition as the essence of life on this earth: Music and genes. Haemotology and Blood Transfusion, 31, 511-518.

Reiss, M., \& Straughan, R. (1996). Improving nature? The science and ethics of genetic engineering. Cambridge: Cambridge University Press.

Rifkin, J. (1998/1999). The biotech century. How genetic commerce will change the world. London: Phoenix.

Sagoff, M. (2003). Genetic engineering and the concept of the natural. In V. Gehring (Ed.), Genetic prospects. Essays on biotechnology, ethics and public policy (pp. 11-26). Lanham: Rowman \& Littlefield.

Sloterdijk, P. (2001). Nicht gerettet. Versuche nach Heidegger. Frankfurt: Suhrkamp.

Spengler, O. (1918/1923). Der Untergang des Abendlandes. Umrisse einer Morphologie der Weltgeschichte. Munchen: Beck.

Thacker, E. (2005). The global genome biotechnology, politics and culture. Cambridge: The MIT Press. Thompson, P. (2003). Unnatural farming and the debate over genetic manipulation. In V. Gehring (Ed.), Genetic prospects. Essays on biotechnology, ethics and public policy (pp. 27-40). Lanham: Rowman \& Littlefield.

Tully, J. (2011). The Devil's milk. A social history of rubber. New York: Monthly Review Press. van der Hout, S. (2014). It's alive ecological genomics and the promise of a new relationship with nature. Nijmegen: Radboud University Nijmegen. 
van Haperen, P., Gremmen, B., \& Jacobs, J. (2012). Reconstruction of the ethical debate on naturalness in discussions about plant-biotechnology. Journal of Agriculture and Environmental Ethics, 25(6), 797-812.

Vogel, S. (1996). Against nature. The concept of nature in critical philosophy. Albany: State University of New York Press.

Zwart, H. (1994). The resurgence of nature-speak. Health Care Analysis, 2(3), 221-226.

Zwart, H. (2009). Biotechnology and naturalness in the genomics era: Plotting a timetable for the biotechnology debate. Journal of Agricultural and Environmental Ethics, 22, 505-529.

Zwier, J., Blok, V., Lemmens, P., \& Geerts, R. J. (2015). The ideal of a zero-waste humanity. Philosophical reflections on the demand for a bio-based economy. Journal of Agricultural and Environmental Ethics (forthcoming). 